\title{
Augmented pedicle trajectory applied on the osteoporotic spine with lumbar degenerative disease: mid-term outcome
}

\author{
Guo-ye Mo ${ }^{1 \dagger}$, Hui-zhi Guo ${ }^{1 \dagger}$, Dan-qing Guo ${ }^{2}$, Yong-chao Tang ${ }^{2}$, Yong-xian Li ${ }^{1,2}$, Kai Yuan², Pei-jie Luo ${ }^{1,2}$,
}

Ten-peng Zhou ${ }^{1,2}$, Shun-cong Zhang ${ }^{1,2^{*}}$ (i) and De Liang ${ }^{2}$

\begin{abstract}
Purpose: To compare the safety and efficiency of cement-augmented pedicle screw with traditional pedicle screw technique applied on the patients in the osteoporotic spine with lumbar degenerative diseases.

Methods: Fifty-six patients followed up at least 2 years were enrolled in our institute with retrospectively reviewed from January 2009 to June 2014, diagnosed as lumbar spondylolisthesis, or lumbar stenosis, with $T$ score $\leq-2.5$ SD of BMD, and received less than three-segment PLIF or TLIF. All patients were divided into 2 groups: 28 (2 males, 26 females) in polymethylmethacrylate-augmented pedicle screw group (PSA) group, the other 28 (3 males, 25 females) in traditional pedicle screw group (TPS). Surgical data including the operation time, intra-operative blood loss, hospitalization day and surgical complications were recorded, as well as the radiological parameters measured from the postoperative $X$-rays and $C T$ scans containing the rates of fusion, screw loosening, and cage subsidence incidence. In addition, the visual analog scores (VAS) and Oswestry Disability Index (ODI) were evaluated preoperatively and postoperatively.
\end{abstract}

Results: The average follow-up period was 34.32 months (ranging from 24 months to 51 months). Compared with PSA group, operation time and average hospital stay in the TPS group decreased significantly $(P<0.05)$. While no statistical difference for blood loss between 2 groups $(P>0.05)$. At 2 years postoperation, from $C T$-scans, 2/172 screws loosening and 1/56 segment non-union occurred in PSA group, with significantly lower incidence than those in TPS group (8/152 screws loosening and 6/50 segments non-union occurred, $P<0.05)$. Regarding the cage subsidence, 24 segments found height loss $(5.30 \pm 1.92 \mathrm{~mm}$ ) in PSA group without difference compared with that of 19 segments (4.78 \pm 1.37 $\mathrm{mm})$ in TPS group $(P>0.05)$. Besides, the number and the location of cages and the leakage of the cement were found out little related with the subsidence in the PSA group $(P>0.05)$. After surgeries, VAS and ODI at 1 month, 6 months, 12 months, and last follow-up improved significantly in two groups $(P<0.05)$. There were no significant differences in VAS and ODI preoperatively and postoperatively between 2 groups $(P>0.05)$. In addition, eight patients with asymptomatic trajectory PMMA leakages were detected.

Conclusion: Cement-augmented pedicle screw technique is effective and safe in the osteoporotic spine with lumbar degenerative diseases, with better fusion rates and less screw loosening incidence. There is no difference in the fusion rate and loosening rate between the two groups in the single segment patients; however, there are better fusion rate and lower pedicle screw loosening rate of the PSA group in the double or multiple group patients.

Keywords: Lumbar degenerative diseases, Osteoporosis, Cement-augmented, Pedicle screw

\footnotetext{
* Correspondence: 18122436960@163.com

${ }^{\dagger}$ Guo-ye Mo and Hui-zhi Guo contributed equally to this work.

'First School of Clinical Medicine, Guangzhou University of Chinese Medicine,

12 Airport Road, Baiyun District, Guangzhou 510405, Guangdong, People's

Republic of China

${ }^{2}$ The First Affiliated Hospital of Guangzhou University of Chinese Medicine,

Guangzhou 510407, China
}

(c) The Author(s). 2019 Open Access This article is distributed under the terms of the Creative Commons Attribution 4.0 International License (http://creativecommons.org/licenses/by/4.0/), which permits unrestricted use, distribution, and

reproduction in any medium, provided you give appropriate credit to the original author(s) and the source, provide a link to the Creative Commons license, and indicate if changes were made. The Creative Commons Public Domain Dedication waiver (http://creativecommons.org/publicdomain/zero/1.0/) applies to the data made available in this article, unless otherwise stated. 


\section{Introduction}

As the aging population accelerates, spates of elder patients are afflicted by the back pain and disability resulted from increasing lumbar degenerative diseases which lead to instability of spine and compression of neural elements. Decompression and fusion surgery combined with pedicle screw fixation system is known as an alternative to address these spinal problems, improving stability and fusion rate [1]. However, fixation failure occurs frequently on these elder patients due to poor bone quality [2]. Many innovations have been developed to increase pullout strength of screws in the osteoporotic spine, such as expanding the length and diameter of the screw, modifying the trajectory, and using an expandable screw and cement-augmented pedicle screw [3-7]. Biomechanical studies have demonstrated increased resistance to failure of the screw-bone interface after augmentation with bone cement. Clinical studies have reported good functional outcomes and very low revision rates with polymethylmethacrylate (PMMA)augmented screws [8].

However, several issues still remained to be unknown: (1) whether polymethylmethacrylate cement impairs the vertebral blood flow, decreasing bone-graft fusion rates; (2) whether the cement compresses the endplate resulting in increasing cage subsidence risks. We used this technique in our institute in cases of 28 patients with degenerative lumbar diseases and followed up the required stability and the severity of complications.

\section{Materials and methods \\ Study population}

All patients provided their informed consent for surgery. The study was approved by the local ethical committee and performed in accordance with the ethical standards of the 1964 Declaration of Helsinki as revised in 2000. From January 2009 to June 2014, surgical procedures were performed by means of a posterior approach using pedicle screws in the lumbar spine for the treatment of lumbar degenerative diseases. Routine lumbar radiographs along with computed tomography $(\mathrm{CT})$ and magnetic resonance imaging (MRI) scans were conducted to confirm the exact nature and level of pathology. Fifty-six patients were furtherly retrospectively reviewed. They were divided into 2 groups; 28 ( 2 males, 26 females) in polymethylmethacrylate-augmented pedicle screw group (PSA), the other 28 (3 males, 25 females) in traditional pedicle screw group (TPS). All patients have received analgesic drug and physiotherapy treatment for more than 3 months. The patients of PSA group were used bone cement-injectable cannulated pedicle screw fixation. Indication for the use of cemented screws was confirmed by evaluating the degree of osteoporosis in all patients. $\mathrm{T}$ score $\leq-2.5 \mathrm{SD}$ was an indication for this technique [9]. Baseline characteristics for clinical information including age, gender, BMI, BMD, diagnosis, and follow-up were collected. All in both groups take vitamin $\mathrm{D}$ and calcium regularly to treat osteoporosis.

\section{Inclusion and exclusion criteria}

Inclusion criteria: (1) The $T$ score of bone mineral density (lumbar vertebrae and one femoral neck, measured by dual-energy X-ray absorptiometry (4500-type, Hologic, USA)) is $\leq-2.5 \mathrm{SD}$; (2) the diagnosis was lumbar spinal stenosis or lumbar spondylolisthesis; (3) less than threesegment posterior lumbar interbody fusion(PLIF)/transforaminal lumbar interbody fusion (TLIF); (4) follow-up time $\geq 2$ years. Exclusion criteria were as follows: (1) spinal infection or tumor; (2) vertebral fracture in fused segment; (3) degenerative scoliosis; (4) parathyroid glands hyperfunction, ankylosing spondylitis, or osteomalacia.

\section{Operative methods}

Under general anesthesia, with the patient in the prone position, the target segments were approached by a posterior midline incision and the facet joint gradually exposed. In the PSA group, fenestrated pedicle screws

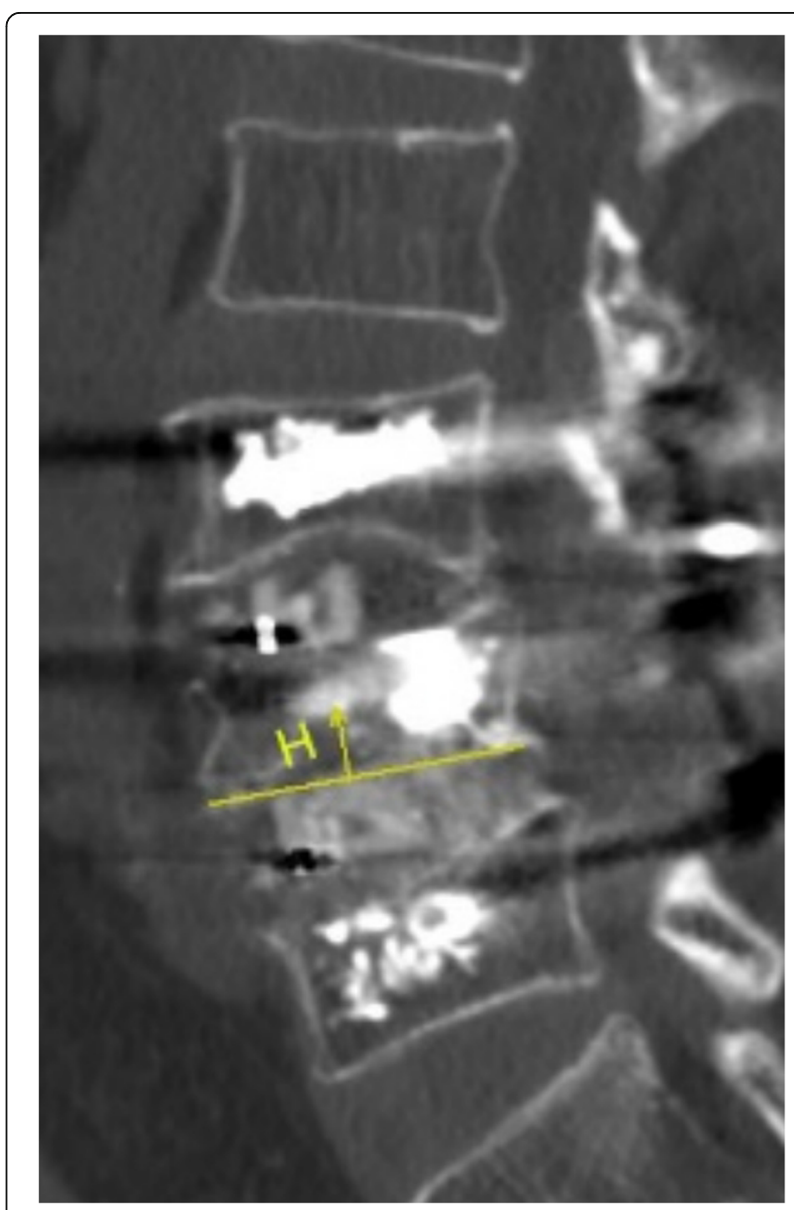

Fig. 1 The measuring method of cage subsidence 
Table 1 Results of demographics

\begin{tabular}{|c|c|c|c|}
\hline & PSA group & TPS group & $P$ value \\
\hline Cases & 28 & 28 & \\
\hline Male/female & $2 / 26$ & $3 / 25$ & 1.000 \\
\hline Diagnosis (LSS/spondylolisthesis) & $15 / 13$ & $18 / 10$ & 0.587 \\
\hline Age (years) & $67.12 \pm 1.31$ & $66.04 \pm 1.08$ & 0.527 \\
\hline Follow-up time (month) & $35.04 \pm 7.39$ & $33.61 \pm 5.36$ & 0.412 \\
\hline BMD & $-3.02 \pm 0.17$ & $-3.01 \pm 0.12$ & 0.971 \\
\hline BMl & $24.38 \pm 0.72$ & $24.59 \pm 0.61$ & 0.828 \\
\hline \multicolumn{4}{|l|}{ Size of subsidence cage } \\
\hline Height (mm) & $10.92 \pm 0.77$ & $10.96 \pm 0.76$ & 0.813 \\
\hline Length (mm) & $23.67 \pm 2.00$ & $24.37 \pm 2.00$ & 0.173 \\
\hline Bone graft & & & 0.752 \\
\hline Allograft bone & 7 & 6 & \\
\hline Autogenous iliac crest bone & 21 & 22 & \\
\hline Fusion segment (single/double/multiple) & $6 / 16 / 6$ & $12 / 10 / 6$ & 0.184 \\
\hline
\end{tabular}

(REACH Medical, Shanghai, P.R. China) were inserted into the lumbar vertebra then approximate $1.5 \mathrm{ml}$ bone cement was injected under the monitoring of fluoroscopy. In the TPS group, the pedicle screws were inserted into the lumbar vertebra. Next, the PLIF/TLIF was carried out. A polyether ether ketone (PEEK) interbody cage, autogenous, and allogeneic bones were used.

\section{Observational parameters}

Surgical data including the operation time, intraoperative blood loss, hospitalization day, and surgical complications were recorded. Radiological parameters measured from the postoperative X-rays and CT scans containing the rates of fusion, screw loosening, lumbar lordosis, and cage subsidence incidence. Radiographic cage subsidence was measured in CT scans from the vertebral endplate to the caudal or cranial margin of the cage (in millimeters) (Fig. 1). The position of the sunk cage was located at anterior, middle, or posterior part of the intervertebral space from the lateral X-ray, and the number was counted from CT. Graft fusion grade was determined with the Bridwell et al. [10] fusion system, only grades 1 and 2 defined as satisfactory fusion. Screw loosening was detected with the translucent shadow around the screw from CT. The data were measured by two experienced spine surgeons. All patients received oral anti-osteoporotic medicine (calcium and vitamin D supplement) at the time being admitted. In addition, the visual analog scores (VAS) and Oswestry Disability Index (ODI) were evaluated preoperatively, at 6 months, 2 years, and the final follow up.

\section{Statistical analysis}

Data collection and statistical analysis were performed using SPPS 22.0 version. Data are reported as the mean, the standard deviation (SD), and the range if continuous, and as the absolute and relative frequencies if categorical. Pre- and postoperative VAS scale scores and ODI values were compared using the $t$ test for independent sample and ANOVA analysis for paired sample. The independent-sample t-test was performed to compare demographics. The number and position of the cage, bone cement in the vertebral body, fusion rate and pedicle screw loosening rate were compared by chi-square test. Statistical significance is at a level of significance of 0.05 .

\section{Results}

\section{Results of demographics}

There are 28 patients in each group. The results of the demographics of the two group were not statistically significant (Table 1).

Table 2 Details about different fusion segment

\begin{tabular}{|c|c|c|c|c|c|}
\hline & \multicolumn{2}{|l|}{ PSA group } & \multicolumn{2}{|l|}{ TPS group } & \multirow[t]{2}{*}{$P$ value } \\
\hline & Non-union segment & Total segments & Non-union segment & Total segments & \\
\hline Single segment & 0 & 6 & 1 & 12 & 0.485 \\
\hline Double/multiple segment & 1 & 50 & 6 & 38 & 0.030 \\
\hline
\end{tabular}


Table 3 Radiographic evaluation operation result

\begin{tabular}{|c|c|c|c|}
\hline & PSA group & TPS group & $P$ value \\
\hline Pedicle screws & 168 & 156 & \\
\hline Fusion segments & 56 & 50 & \\
\hline Non-union rate & $1 / 56$ & $7 / 50$ & $0.028^{*}$ \\
\hline Loosening rate & $2 / 168$ & $8 / 156$ & $0.047^{*}$ \\
\hline \multicolumn{4}{|l|}{ Lumber lordosis $\left(^{\circ}\right)$} \\
\hline Pre-operation & $32.71 \pm 11.71$ & $29.83 \pm 13.87$ & 0.415 \\
\hline Post-operation & $32.02 \pm 10.41$ & $28.60 \pm 11.17$ & 0.251 \\
\hline Final follow-up & $34.59 \pm 11.80$ & $30.47 \pm 10.05$ & 0.173 \\
\hline Operation time (min) & $266.30 \pm 14.51$ & $204.90 \pm 10.35$ & $0.002^{*}$ \\
\hline Blood loss (ml) & $605.0 \pm 121.90$ & $648.10 \pm 89.77$ & 0.725 \\
\hline Hospital stays (day) & $23.69 \pm 1.44$ & $19.44 \pm 1.18$ & $0.026^{*}$ \\
\hline Number of subsidence cage (one/two) & $12 / 12$ & $11 / 8$ & 0.606 \\
\hline Position of subsidence cage & & & 0.983 \\
\hline Anterior middle posterior & 16 & 13 & \\
\hline Anterior middle & 6 & 4 & \\
\hline Middle posterior & 2 & 2 & \\
\hline Subsidence height(mm) & $5.30 \pm 1.92$ & $4.78 \pm 1.37$ & 0.606 \\
\hline
\end{tabular}

Note: ${ }^{*} P<0.05$

\section{Results of radiographic evaluation}

There were two pedicle screws loosening in the PSA and eight pedicle screws loosening in the TPS. The screw loosening rate of PSA group was $1.16 \%$, which was lower than $5.26 \%$ of the TPS group. There was no non-union in the single segment of the PSA group, but one nonunion segment in the TPS group. However, there was one non-union segment and six non-union segments in double or multiple segments patients of PSA group and TPS group, respectively (Table 2). The fusion rate or PSA group was $98.21 \%$, which higher than $86.00 \%$ of TPS group. They were statistically significant. The average operative time, $266.30 \pm 14.51 \mathrm{~min}$, and hospital stays, $23.69 \pm 1.44$ days, of PSA group were greater than TPS group, and they were statistically significant. There were 24 cages subsidence in the PSA group and 19 cages subsidence in the TPS group, and the subsidence height of the PSA group was $5.30 \pm 1.92 \mathrm{~mm}$ higher than 4.78 $\pm 1.37 \mathrm{~mm}$ of the TPS group. But they were not statistically significant. In the PSA group, 24 fusion segment cages arose subsidence and 32 fusion segment cages were normal. $33.33 \%$ cage subsidence associated with cement leakage and the leakage rate of the normal fusion segment cages was $25 \%$, but there was no significant difference. The typical case of PSA group was in Fig. 2. All the cement leakage was paravertebral leakage, without obvious clinical symptoms. The number and position of cage and the leakage of bone cement were not associated with cage subsidence (Tables 3 and 4).

\section{Clinical results}

The preoperative VAS and ODI of the PSA group were $7.75 \pm 0.75$ and $36.61 \pm 2.17$, respectively, and they were higher than the postoperative. Similarly, the preoperative VAS and ODI of TPS group were 7.64 \pm 0.91 and 37.14 \pm 2.17 , respectively, which were higher than the postoperative. They were statistically significant. There was no significant difference between the two groups (Figs. 3 and 4$)$.

\section{Discussion}

One of the goals for treating lumbar degenerative disease is to decompress and achieve the stability of the spine [11]. Pedicle screw loosening reported as the common complication may lead to the failure of fusion in osteoporotic spine with a rate from 0.6 to $11 \%[5,12-14]$. According to the report, $60 \%$ of pull-out strength of pedicle screw comes from the vertebral cancellous bone [15]. The

Table 4 Details about cage subsidence in the PSA group

\begin{tabular}{llll}
\hline & Subsidence & Normal & $P$ value \\
\hline Fusion segments & 24 & 32 & \\
Number of cage (one/two) & $12 / 12$ & $17 / 15$ & 0.817 \\
Position of cage & & & 0.653 \\
Anterior middle posterior & 16 & 20 & \\
Anterior middle & 6 & 8 & \\
Middle posterior & 2 & 4 & \\
Cement leakage & 8 & 8 & 0.495 \\
\hline
\end{tabular}

Note: * $P<0.05$ 


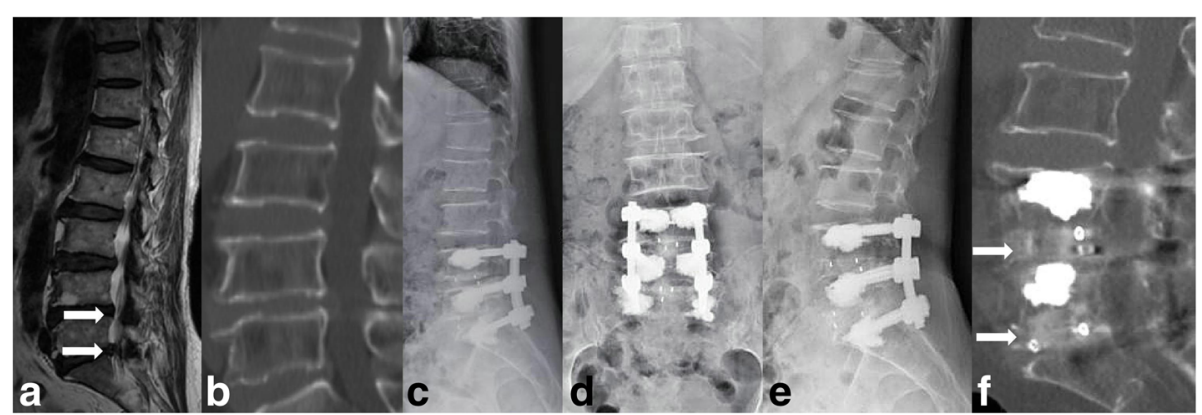

Fig. 2 Radiological images of a representative case with polymethylmethacrylate-augmented pedicle screw treatment. a-f A 67-year-old female with lumbar spinal stenosis in L4/5 and L5/S1 segments. a Preoperative MRI image showed obvious spinal stenosis in L4/5 and L5/S1 segments (white arrow). b Preoperative CT scanning showed no osteophyte in posterior of vertebrae. c-d Postoperative X-ray showed the normal position of pedicle screws and the cement in the vertebrae. e Lateral X-ray at 36 months after fusion surgery showed normal position of pedicle screws. f Lumber $C T$ scanning at 36 months after fusion surgery showed series cancellous bone through L4/5 and L5/S1 intervertebral space (white arrow)

high risk of screw loosening in osteoporotic spine is due to the fragile bone with a rate of $4.1-12.9 \%$ [16]. Considering the traditional pedicle screw unsatisfactory performance in the poor-quality spine, cementedaugmented pedicle screws have been an alternative to strengthen the anti-pullout capability by dosing cement carefully through the screws into the vertebral body. Some researchers reviewed cases using 158 cement-augmented pedicle screws, no screw loosening found [16]. In our study, the 178 cement-augmented pedicle screws with a loosening rate of $1.16 \%$, significantly lower than the traditional pedicle screws with a rate of $5.26 \%$ in osteoporotic spine at 2-year followup. Among the screws loosened, screws at S1 were observed more, probably ascribing to the great shear force based on the aslant anatomic structure of S1.

Successful intervertebral graft bone fusion is based on segmental stability. Screw loosening is reportedly associated with graft bone non-union, pseudoarthrosis, and secondary kyphosis $[17,18]$. Pedicle screw augmentation is demonstrated capable to improve the stability of the instrumentation and achieve satisfactory fusion with a rate from 92.50 to $100 \%$ in poor spinal bone [19-22]. Similarly, in this study, the fusion rate of the PSA group achieved $98.2 \%$, higher than $86.0 \%$ of TPS group. In the PSA group, one case has non-union with pedicle screw loosening, whereas seven cases of TPS group have nonunion, including three cases with pedicle screw loosening. The L5/S1 segment non-union case of PSA group is a 56year-old female suffering from rheumatoid arthritis and long-term use of glucocorticoid. Her $T$ value of lumbar bone mineral density is -3.5 , and 2 screws of S1 become loose. The study suggested that there no difference in single segment fusion rate between the two groups. But the non-union rate of PSA group was lower than TPS group in the double or multiple segments.

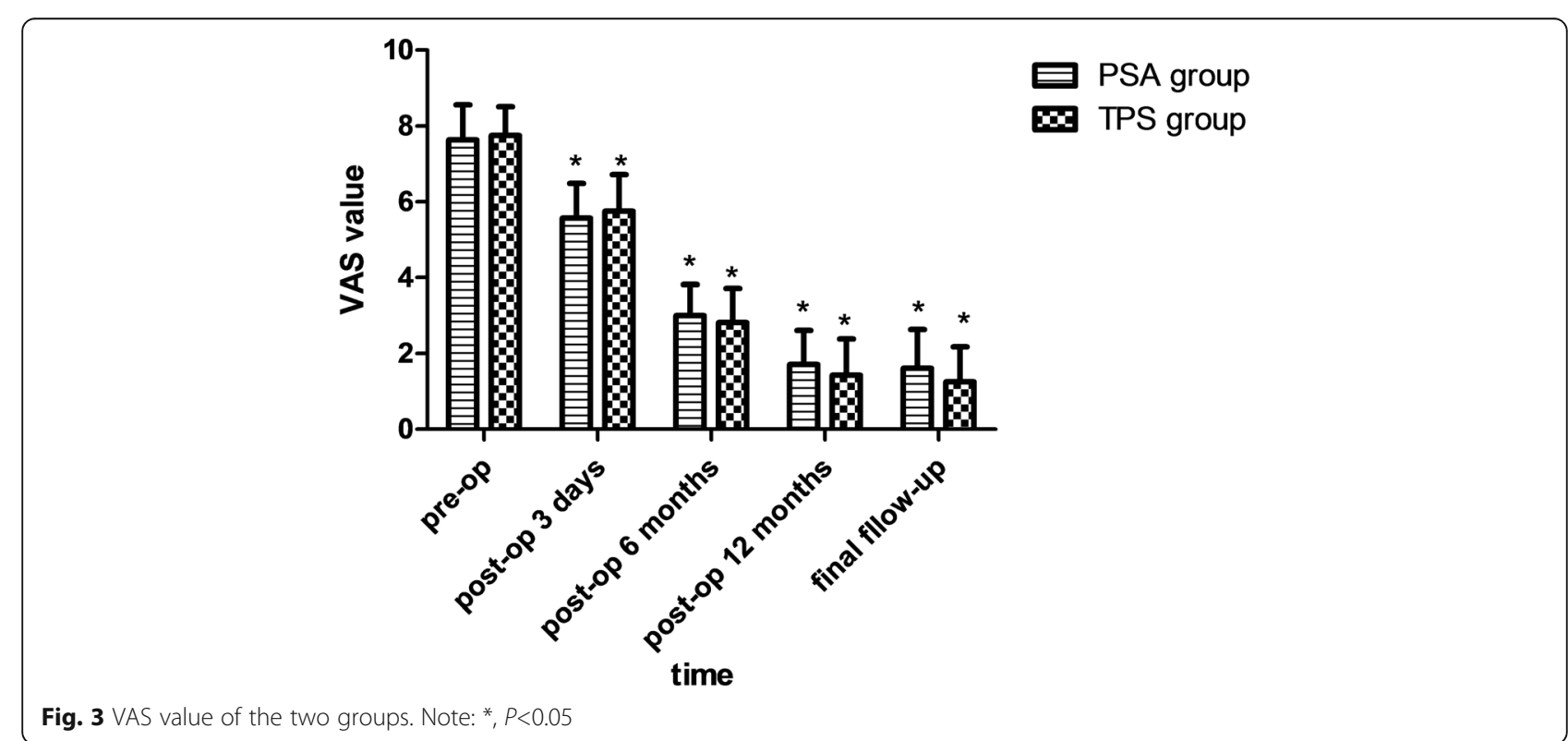




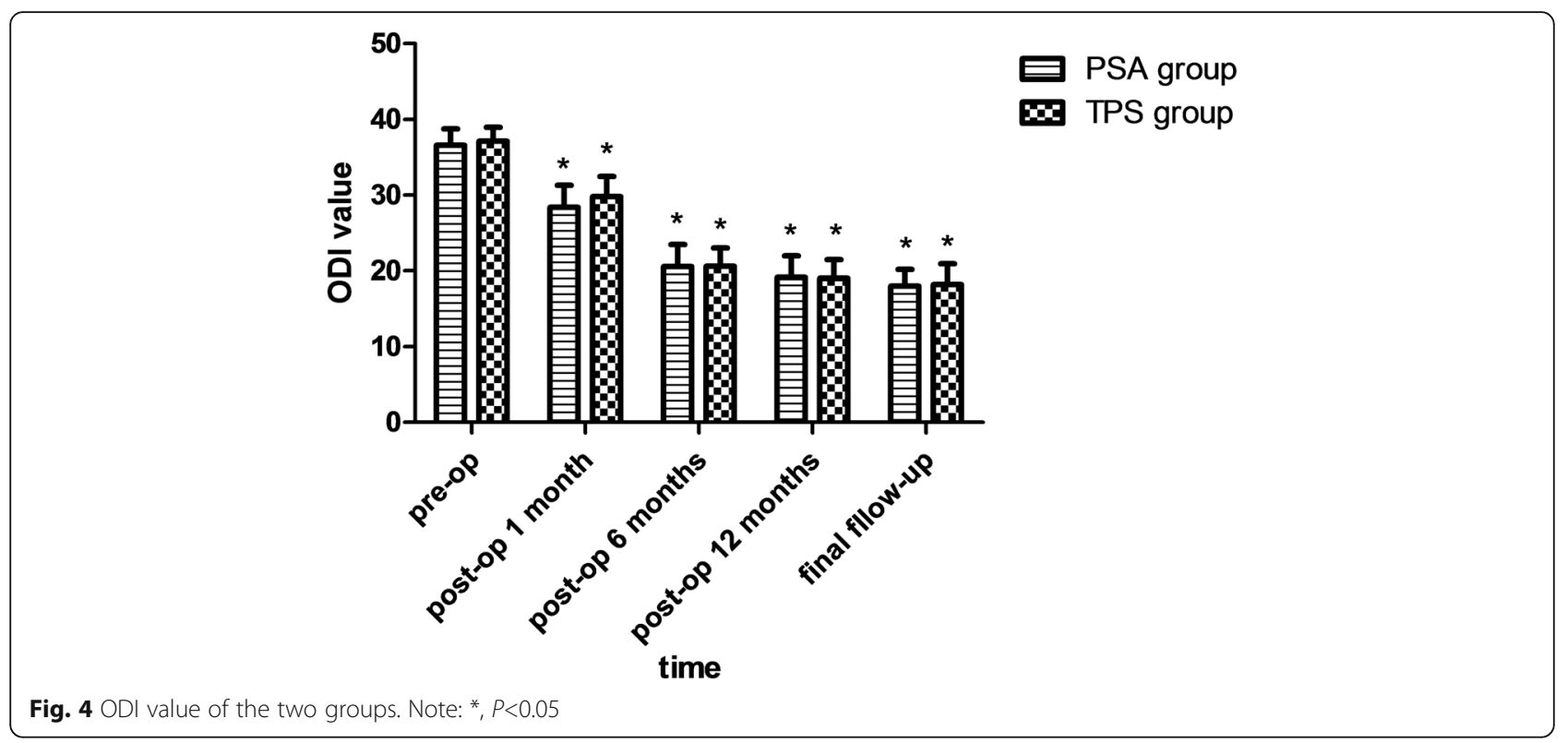

The goals for inserting cage in intervertebral body are the restoration of intervertebral height, maintainment of spinal balance, and segmental stability. Cage subsidence as a common postoperative complication may result in recollapse of intervertebral foramen, leading to new neurological compression [23]. The rate of cage subsidence was as high as $22 \%$ in posterior lumbar interbody fusion $[24,25]$. However, we detected 24 segments with cage subsidence $(42.86 \%)$ in the PSA group and $19(38 \%)$ in TPS group. Because the bone mineral density of patients in this study is lower, the cage subsidence rate of the two groups is higher. The cage subsidence height, $(5.30 \pm 1.92)$ $\mathrm{mm}$, in the PSA group is larger than the TPS group, $(4.78 \pm 1.37) \mathrm{mm}$, but the difference is not statistically significant. The different position of the cage was revealed to be associated with the difference of lumbar lordotic restoration [11]; however, the paucity of literature reported the association with subsidence and the cage position. The different positions of cage lead to different stress of the vertebral endplate. But based on our result, the position of the cage is not associated with subsidence. We also found that the distribution of bone cement in vertebral body and cement leakage are not related to cage subsidence in the PSA group.

Regarding pain relief and function improvement, PSA group enjoyed a satisfactory result as much as TPS group did. The operation time and hospital stay of PSA group are longer than TPS group. Using polymethylmethacrylate-augmented pedicle screw needs more operation time in the PSA group with more blood loss than TPS group, although there is no statistical significance.
There some limitations to the study. Firstly, it is a retrospective analysis with small sample size. A prospective study is necessary to further confirm the differences observed. Theoretically, the cage subsidence should subtract in PSA group with less pressure from endplate on the cage due to the strength bared more by screws augmented providing enough segmental stability than traditional screw. But our statistic result is negative. We need further enlarged sample to confirm it. Thirdly, we blended the cases with different numbers of fusion segments to analyze, as a consequence, which may increase the bias of conclusion because the bone fusion, screw loosening, and cage subsidence were affected by pressure differed in single, double, or multiple segmental fixations.

\section{Conclusion}

Cement-augmented pedicle screw technique is effective and safe in the osteoporotic spine with lumbar degenerative diseases, with better fusion rates and less pedicle screw loosening incidence. There is no difference in the fusion rate and pedicle screw loosening rate between the two groups in the single segment patients; however, there are better fusion rate and lower pedicle screw loosening rate of the PSA group in the double or multiple group patients.

\section{Abbreviations}

CT: Computed tomography; MRI: Magnetic resonance imaging; ODI: Oswestry Disability Index; PLIF: Posterior lumbar interbody fusion; PMMA: Polymethylmethacrylate; PSA: Polymethylmethacrylate-augmented pedicle screw group; SD: Standard deviation; TLIF: Transforaminal lumbar interbody fusion; TPS: Traditional pedicle screw; VAS: Visual analog scores

\section{Acknowledgements}

The authors extend their thanks to DaXing Li and Guangwei Wen for their kind help in the data extraction and statistical analysis processes. 


\section{Authors' contributions}

GYM and HZG conceived and designed the study. DQG and YCT collected and processed the data. GYM and YXL wrote the paper. GYM, PJL, TPZ, SCZ, and $\mathrm{DL}$ reviewed and edited the manuscript. All authors read and approved the final manuscript

\section{Funding}

This work was supported by grants from the Guangzhou science and technology project (201707010460) and Guangdong science and technology project (2016A020215137)

\section{Availability of data and materials}

The datasets used and analyzed during the current study are available from the corresponding author on reasonable request.

\section{Ethics approval and consent to participate}

The study was approved by the Ethics Committee of The First Affiliated Hospital of Guangzhou University of Chinese Medicine and performed in accordance with the ethical standards of the 1964 Declaration of Helsinki as revised in 2000. All patients provided their informed consent for surgery.

\section{Consent for publication}

Not applicable

\section{Competing interests}

The authors declare that they have no competing interests.

\section{Received: 29 October 2018 Accepted: 22 May 2019}

Published online: 06 June 2019

\section{References}

1. Lonstein JE, Denis F, Perra JH, Pinto MR, Smith MD, Winter RB. Complications associated with pedicle screws. J Bone Joint Surg Am. 1999; 81:1519-28.

2. Halvorson TL, Kelley LA, Thomas KA, Whitecloud TS, Cook SD. Effects of bone mineral density on pedicle screw fixation. Spine (Phila Pa 1976). 1994; 19:2415-20.

3. Polly DW, Orchowski JR, Ellenbogen RG. Revision pedicle screws. Bigger, longer shims—what is best. Spine (Phila Pa 1976). 1998;23:1374-9.

4. Kuhns CA, Reiter M, Pfeiffer F, Choma TJ. Surgical strategies to improve fixation in the osteoporotic spine: the effects of tapping, cement augmentation, and screw trajectory. Global Spine J. 2014;4:47-54. https:// doi.org/10.1055/s-0033-1361588.

5. Pfeiffer FM, Abernathie DL, Smith DE. A comparison of pullout strength for pedicle screws of different designs: a study using tapped and untapped pilot holes. Spine (Phila Pa 1976). 2006;31:E867-70. https://doi.org/10.1097/ 01.brs.0000244658.35865.59.

6. Cook SD, Salkeld SL, Stanley T, Faciane A, Miller SD. Biomechanical study of pedicle screw fixation in severely osteoporotic bone. Spine J. 2004;4:402-8. https://doi.org/10.1016/j.spinee.2003.11.010.

7. Cameron HU, Jacob R, Macnab I, Pilliar RM. Use of polymethylmethacrylate to enhance screw fixation in bone. J Bone Joint Surg Am. 1975;57:655-6.

8. Dai F, Liu Y, Zhang F, Sun D, Luo F, Zhang Z, Xu J. Surgical treatment of the osteoporotic spine with bone cement-injectable cannulated pedicle screw fixation: technical description and preliminary application in 43 patients. Clinics (Sao Paulo). 2015;70:114-9. https://doi.org/10.6061/dinics/2015(02)08.

9. Glassman SD, Alegre GM. Adult spinal deformity in the osteoporotic spine: options and pitfalls. Instr Course Lect. 2003;52:579-88 doi.

10. Bridwell KH, Lenke LG, McEnery KW, Baldus C, Blanke K. Anterior fresh frozen structural allografts in the thoracic and lumbar spine. Do they work if combined with posterior fusion and instrumentation in adult patients with kyphosis or anterior column defects. Spine (Phila Pa 1976). 1995;20:1410-8.

11. Park SJ, Lee CS, Chung SS, Kang SS, Park HJ, Kim SH. The ideal cage position for achieving both indirect neural decompression and segmental angle restoration in lateral lumbar interbody fusion (LLIF). Clin Spine Surg. 2016. https://doi.org/10.1097/BSD.0000000000000406.

12. Esses SI, Sachs BL, Dreyzin V. Complications associated with the technique of pedicle screw fixation. A selected survey of ABS members. Spine (Phila Pa 1976). 1993;18:2231-8; discussion 2238-2239. doi:.

13. Okuyama K, Abe E, Suzuki T, Tamura Y, Chiba M, Sato K. Can insertional torque predict screw loosening and related failures? An in vivo study of pedicle screw fixation augmenting posterior lumbar interbody fusion. Spine (Phila Pa 1976). 2000;25:858-64

14. Wittenberg RH, Shea M, Swartz DE, Lee KS, White AA, Hayes WC. Importance of bone mineral density in instrumented spine fusions. Spine (Phila Pa 1976). 1991;16:647-52.

15. Hirano T, Hasegawa K, Takahashi HE, Uchiyama S, Hara T, Washio T, Sugiura T, Yokaichiya M, Ikeda M. Structural characteristics of the pedicle and its role in screw stability. Spine (Phila Pa 1976). 1997;22:2504-9; discussion 2510. doi:.

16. Frankel BM, Jones T, Wang C. Segmental polymethylmethacrylateaugmented pedicle screw fixation in patients with bone softening caused by osteoporosis and metastatic tumor involvement: a clinical evaluation. Neurosurgery. 2007;61:531-7; discussion 537-538. https://doi.org/10.1227/01. NEU.0000290899.15567.68.

17. Berjano P, Bassani R, Casero G, Sinigaglia A, Cecchinato R, Lamartina C. Failures and revisions in surgery for sagittal imbalance: analysis of factors influencing failure. Eur Spine J. 2013;22(Suppl 6):S853-8. https://doi.org/10 1007/s00586-013-3024-x.

18. McLain RF, Sparling E, Benson DR. Early failure of short-segment pedicle instrumentation for thoracolumbar fractures. A preliminary report. J Bone Joint Surg Am. 1993;75:162-7.

19. Amendola L, Gasbarrini A, Fosco M, Simoes CE, Terzi S, De lure F, Boriani S Fenestrated pedicle screws for cement-augmented purchase in patients with bone softening: a review of 21 cases. J Orthop Traumatol. 2011;12:1939. https://doi.org/10.1007/s10195-011-0164-9.

20. Wittenberg RH, Lee KS, Shea M, White AA, Hayes WC. Effect of screw diameter, insertion technique, and bone cement augmentation of pedicular screw fixation strength. Clin Orthop Relat Res. 1993; 296:278-87.

21. Pfeifer $B A$, Krag MH, Johnson C. Repair of failed transpedicle screw fixation. A biomechanical study comparing polymethylmethacrylate, milled bone, and matchstick bone reconstruction. Spine (Phila Pa 1976). 1994;19:350-3.

22. Paré PE, Chappuis JL, Rampersaud R, Agarwala AO, Perra JH, Erkan S, Wu C. Biomechanical evaluation of a novel fenestrated pedicle screw augmented with bone cement in osteoporotic spines. Spine (Phila Pa 1976). 2011;36: E1210-4. https://doi.org/10.1097/BRS.0b013e318205e3af.

23. Chen L, Yang H, Tang T. Cage migration in spondylolisthesis treated with posterior lumbar interbody fusion using BAK cages. Spine (Phila Pa 1976). 2005:30:2171-5.

24. Vaidya R, Sethi A, Bartol S, Jacobson M, Coe C, Craig JG. Complications in the use of rhBMP-2 in PEEK cages for interbody spinal fusions. J Spinal Disord Tech. 2008;21:557-62. https://doi.org/10.1097/BSD. ob013e31815ea897.

25. Vaidya R, Weir R, Sethi A, Meisterling S, Hakeos W, Wybo CD. Interbody fusion with allograft and rhBMP-2 leads to consistent fusion but early subsidence. J Bone Joint Surg Br. 2007:89:342-5. https://doi.org/10.1302/ 0301-620X.89B3.18270.

\section{Publisher's Note}

Springer Nature remains neutral with regard to jurisdictional claims in published maps and institutional affiliations.

Ready to submit your research? Choose BMC and benefit from:

- fast, convenient online submission

- thorough peer review by experienced researchers in your field

- rapid publication on acceptance

- support for research data, including large and complex data types

- gold Open Access which fosters wider collaboration and increased citations

- maximum visibility for your research: over $100 \mathrm{M}$ website views per year

At BMC, research is always in progress.

Learn more biomedcentral.com/submissions 